\title{
Photodynamic Therapy: Cavitary Photoillumination of Malignant Cerebral Tumours Using a Laser Coupled Inflatable Balloon
}

\author{
Paul J. Muller and Brian C. Wilson
}

\begin{abstract}
Interest in photodynamic therapy of malignant brain tumours has been growing in recent years as intra-operative laser applications become more available.

We have developed an inflatable balloon which can be coupled to an argon dye pump laser in order to deliver light to a brain tumour cavity created by the subtotal resection of tumour. Eight patients with primary malignant brain tumours have been treated with photodynamic therapy (PDT) using this device. The 8 patients tolerated the treatment well; morbidity attributable to the PDT was acceptably low.
\end{abstract}

\begin{abstract}
RÉSUMÉ: Thérapie photodynamique: photo-éclairage cavitaire des tumeurs cérébrales malignes en utilisant un ballon gonflable associé à un laser L'intérêt dans la thérapie photodynamique des tumeurs malignes du cerveau augmente depuis que les applications du laser se font sentir lors des opérations. Nous avons développé un ballon gonflable qui peut être couplé à un laser à pompe de teinture d'argon. Cet instrument conduit la lumière à la cavité produite par la résection sous-totale de la tumeur cérébrale. Nous avons aussi traité 8 patients atteints de tumeurs cérébrales primaires malignes à l'aide de cet instrument. Les 8 patients ont bien toléré la thérapie photodynamique pour laquelle la morbidité associée est suffisamment basse.
\end{abstract}

Can. J. Neurol. Sci. 1985; $12: 371-373$

Photodynamic therapy (PDT) consists of the exposure of neoplastic tissue to visible light of an appropriate wavelength to activate a photosensitizer administered prior to photoillumination. The photosensitizer must have the tendency to be selectively retained by the malignant tissue and must interact with light to cause a chemically mediated destruction or sterilization of tumour cells. Hematoporphyrin derivative (HPD), an acidification product of hematoporphyrin (HP), has been the most widely studied photosensitizer. ${ }^{1}$

HP is a naturally occurring compound with a chemical structure similar to the heme moiety of hemaglobin. It does not contain iron, however. It has long been recognized that HP is concentrated in tumour tissue and mediates photochemical reactions when exposed to light. ${ }^{2}$ Hematoporphyrin derivative (HPD) is a compound of greater tumour specificity than its parent HP. ${ }^{3}$ HPD accumulates in tissues that have a rapid cellular turnover, reaches a maximal tissue concentration at 3 hours after administration, and remains in tumour tissue a minimum of 3 days after administration. ${ }^{4}$

The absorption spectrum of HPD consists of much of the visible light range, from the near-ultraviolet to red, with 5 wavelength peaks. Effective activation of the HPD can be achieved by photoillumination of the HPD containing tissue with any of these 5 absorption peaks. The application of blueviolet light at (405 $\mathrm{nm}$ wavelength) results in HPD activation and fluorescence at relatively low levels of photic energy. When greater photic energy is applied, cytotoxic effects occur through the photochemical production of free radicals ${ }^{5}$; singlet oxygen is considered the primary cytotoxic agent. ${ }^{6}$

The longer the wavelength, the greater is the tissue penetration of light. Therefore, a wavelength that corresponds to the last absorption peak of HPD $(632 \mathrm{~nm})$ is used for PDT although this wavelength is less effective for the photoactivation of HPD than are the shorter wavelength peaks. ${ }^{\text {? }}$ 
Dougherty et al have treated a variety of superficial metatastic lesions by PDT with a reported response rate of greater than $90 \%{ }^{8}$ Dahlman et al ${ }^{9}$ achieved similar results in 37 patients with superficial metatastic carcinoma.

Experience in the PDT of malignant brain tumours is limited. Perria et al ${ }^{10}$ were the first to use PDT in the treatment of malignant brain tumours. After tumour resection they utilized intraoperative cavitary PDT administering the light with a $\mathrm{He}-\mathrm{Ne}$ laser; 9 patients were treated; none received postoperative radiation therapy and their survival ranged from 6-44 weeks. No significant complications of the PDT were reported. Laws et $\mathrm{al}^{4}$ have carried out a phase I feasibility study utilizing HPD-PDT in the treatment of recurrent malignant brain tumours. They used an argon dye pump laser coupled to a fiber optic probe inserted into the tumour by stereotactic means. No neurological complications occurred as a consequence of photoradiation therapy. More recently Laws reported 22 patients with malignant brain tumours treated at the Mayo Clinic; 2 developed wound infections and 2 had transient worsening of neurologic function."

McCulloch et al ${ }^{12}$ have used PDT therapy in the treatment of malignant brain tumours. They treated 5 patients with metastatic disease. One patient had a postradiotherapy recurrence and survived 11 months after PDT. Two patients, who did not undergo radiotherapy, were alive after 16 and 10 months without evidence of recurrence. One patient with a malignant melanoma died two months after PDT. They treated 9 patients with malignant astrocytoma. All 9 underwent radical tumour extirpation, and PDT consisting of $5 \mathrm{mg} / \mathrm{kg}$ HPD and a total light dose of 2000-2500 Joules at a wavelength of $230-240 \mathrm{~nm}$. Three of the 9 patients were alive 17-42 months after treatment. The complication rate was small.

We are reporting our experience with intraoperative PDT in 8 patients with primary malignant brain tumours using a photoilluminating device which consisted of an inflatable balloon coupled to an argon dye pump laser in order to deliver light to a tumour cavity created by radical subtotal resection.

\section{Materials AND METHOdS}

Patient Population: Eight patients with malignant supratentorial primary brain tumours were selected for PDT. Three patients had glioblastoma multiforme, 3 had malignant astrocytomas, one had a gliosarcoma and one a primitive neuroectodermal tumour. In 7 of the 8 cases the tumour had recurred and PDT was utilized as a component of their surgical palliation. There were 4 males and 4 females whose ages ranged from 17 to 59 . Table 1 summarizes the clinical data, previous treatment and PDT parameters.

Hematoporphyrin Derivative: HPD (Photofrin I) was purchased from Photoforin Inc., Cheektowaga, New York. The HPD was administered by injection over ten minutes through an intravenous line which was infusing $5 \%$ dextrose in saline. A total dose of $150 \mathrm{mg}$ was administered to each patient 24 hours prior to intraoperative photoillumination. The HPD dose ranged from 2 to $2.5 \mathrm{mg} / \mathrm{kg}$ body weight. After the administration of HPD patients were kept in a subdued light environment for 7 days and advised to avoid direct and indirect sunlight for one month.

Table 1. Photo-chemotherapy of Primary Malignant Brain Tumours

\begin{tabular}{|c|c|c|c|c|c|c|c|c|}
\hline & 1 & $\underline{2}$ & 3 & 4 & 5 & 6 & 7 & 8 \\
\hline Age & 49 & 53 & 32 & 17 & 59 & 44 & 35 & 27 \\
\hline Sex & $\mathrm{F}$ & $\mathrm{F}$ & $\mathrm{F}$ & $\mathbf{M}$ & $\mathrm{F}$ & M & $\mathbf{M}$ & $\mathbf{M}$ \\
\hline Prev Surg & + & - & + & + & + & + & + & + \\
\hline Prev Radio & - & - & + & + & + & + & + & + \\
\hline Prev Chemo & - & - & - & + & - & + & - & - \\
\hline \multicolumn{9}{|l|}{ Clinical: } \\
\hline Headache & + & + & + & - & + & + & + & - \\
\hline Drowsy & + & - & - & - & - & + & - & - \\
\hline Dementia & - & - & _- & - & + & - & _- & - \\
\hline Hemiparesis & - & - & + & - & - & - & - & + \\
\hline Field Defect & - & - & - & + & _- & _- & - & - \\
\hline Dysphasia & - & - & - & + & - & - & - & - \\
\hline Karnofsky & 40 & 80 & 60 & 80 & 70 & 50 & 90 & 60 \\
\hline Pathology: & GS & GBM & GBM & PNET & MA & GBM & MA & MA \\
\hline \multicolumn{9}{|l|}{ PDT } \\
\hline Total Joules & 439 & 840 & 810 & 1575 & 1435 & 2250 & 2350 & 3888 \\
\hline Joules $/ \mathrm{cm}^{2}$ & 8 & 15 & 18 & 24 & 35 & 42 & 50 & 68 \\
\hline HPD [total dose] & 150 & 150 & 150 & 150 & 150 & 150 & 150 & 150 \\
\hline $\mathrm{HPD}[\mathrm{mg} / \mathrm{kg}]$ & 2.3 & 2.5 & 1.9 & 2.0 & 2.1 & 2.1 & 2.0 & 1.9 \\
\hline Outcome to Date & Prog & Stable & Prog & Dead & Stable & Dead & Stable & Stable \\
\hline Complication & None & None & None & Infect & None & None & None & DVT \\
\hline Post-PDT Deficit & No & No & No & No & No & No & No & No \\
\hline
\end{tabular}


Surgical Treatment and Photoillumination: Twenty-four hours after administration of HPD the patients were taken to the operating room where a maximal tumour resection was carried out. The resulting tumour cavity was photoilluminated using an inflatable balloon coupled to an argon dye pump laser (Model 770, Copper Medical, Mountainview, California).

The balloon illuminating device ${ }^{13}$ consists of a metal cylinder $16 \mathrm{~cm}$ in length and $1.6 \mathrm{~cm}$ in external diameter. There were three channels through the length of the cylinder, a central channel and two side channels. The central channel was used to conduct a 300 micron fiber probe which was coupled to the laser. The end of the fiber protruded into a balloon made of the cut middle finger of a surgical glove. The depth of penetration was determined by the balloon volume so that the probe tip was approximately in the centre of the balloon at the time of inflation. The balloon was inflated via one of the side channels which ran from the input ports of the cylinder to its cerebral end. The degree of balloon inflation was such as to produce a snug fit in the tumour cavity. The balloon was inflated with a 1:1000 dilution of sterile nutralipid which has been shown to be an ideal light dispersion medium. ${ }^{13}$

Light Dose: Table 1 summarizes the light doses used. For each case the laser was tuned to a wavelength of $632 \mathrm{~nm}$ and the wavelength was confirmed with a spectroscope (26-6270 Hartridge revison spectroscope). The fiber probe output was measured with a radiometer/photometer (Photodyne model $88 \mathrm{XLA}$, model 350 sensor head) in order to assure the accuracy of the light dose determinations. The total light energy delivered ranged from 439 to 3888 Joules and the light dose ranged from 8 to 68 $\mathrm{J} / \mathrm{cm}^{2}$.

\section{RESULTS}

There were no adverse photo-sensitivity skin reactions. No acute post-operative neurologic deterioration occurred in the 8 patients treated. However, 3 of the 8 underwent clinical deterioration as a consequence of tumour progression within 2 months of PDT; these patients died 55, 89 and 200 days after PDT.

Two patients developed wound infections; one of these required surgical drainage and removal of the infected bone flap and the second, whose infection was superficial, required only antibiotic therapy. Two patients, both of whom were severely hemiparetic, developed deep leg vein thrombosis and required anticoagulant therapy.

\section{Discussion}

The prognosis of patients with primary malignant brain tumours treated by conventional means, including surgical resection, radiotherapy and chemotherapy remains very poor; the median survival for patients with malignant astrocytic tumours who undergo optimum therapy is approximately one year. The search for additional modes of treatment must be pursued in order to improve survival. Photodynamic therapy of malignant brain tumours has only recently been initiated and no adequate evaluation of its efficacy will be available until much greater experience has accrued.

It has been suggested that the intensity of the light dose should not exceed $30-35 \mathrm{~J} / \mathrm{cm}^{2}$ since toxicity has been observed at higher levels. ${ }^{14}$ In our series the light dose was escalated to 68 $\mathrm{J} / \mathrm{cm}^{2}$ with no acute post-operative deterioration. In part, this may be the consequence of a relatively conservative dose of HPD since the tissue effect of PDT is dependent on both light intensity and HPD concentration.

In conclusion we have demonstrated the following:

1. Intraoperative cavitary photoillumination of the brain can be performed with relative safety.

2. Intraoperative light dose administration can be measured with relative accuracy.

Further studies, both laboratory and clinical, will be needed to determine the efficacy of photodynamic therapy in the treatment of malignant brain tumours.

\section{REFERENCES}

1. Dougherty TJ, Weishaupt KR, Boyle DG. Photosensitizers. In: DeVita VT, Helman S, Rosenberg SA (eds). Cancer. Philadelphia: JP Lippincott, 1982.

2. Auler $H$, Banzer $G$. Untersuchungen uber die rolle der prophine bei geschwulstkranken menschen und tieren. Z Krebsforsch, 1924; 53:65-69.

3. Lipson RL, Baldes EJ, Olsen AM. The use of a derivative of hematoporphyrin in tumor detection. J Nat Cancer Inst, 1961; 26:1-11.

4. Laws ER, Cortese DA, Kinsey JH, et al. Photoradiation therapy in the treatment of malignant brain tumors: A feasibility study. Neurosurgery 1981; 9:672-678.

5. Kohn K, Kessel D. On the mode of cytotoxic action of photoactivated porphyrins. Biochem Pharmacol, 1979; 28:2465-2470.

6. Weishaupt KR, Gomer CJ, Dougherty TJ. Identification of singlet oxygen as the cytotoxic agent in photo-inactivation of a murine tumor. Cancer Res, 1976; 36:2326-2329.

7. Wilson BC, Jeesves WP. Photodynamic therapy in cancer. In: Ben-Hur E and Rosenthal I (eds). Photomedicine. Cleveland: CRC Press Inc. (in press).

8. Dougherty TJ, Lawrence G, Kaufman JH, et al. Photoradiation therapy in the treatment of recurrent breast carcinoma. J Nat Cancer Inst, 1979; 62:231-237.

9. Dahlman A, Wile AG, Burns RG, et al. Laser photoradiation therapy of cancer. Cancer Res, 1983; 43:430-434.

10. Perria C, Capuzzo T, Cavagnaro G, et al. First attempts at the photodynamic therapy of human gliomas. J Neurosurg Sci, 1980; 24:119-129.

11. Laws ER, Wharen JR. RE: Comments. Neurosurgery 1984; 15: 808-809.

12. McCulloch GAJ, Forbes IJ, Lee See K, et al. Phototherapy in malignant brain tumors. In: Doiron DR, Gomer CJ (eds). Porphyrin Localization and Treatment of Tumors. New York: A.R. Liss Inc., 1984:709-718.

13. Wilson BC, Muller PJ, Yanche JC. Instrumentation and light dosimetry for intraoperative photodynamic therapy (PDT) of malig. nant brain tumors. Physics in Med and Biol (in press).

14. Appuzzo ML. Comments. Neurosurgery 1984; 15:809-810. 